\title{
Environmentally-Induced Displacement and Human Security
}

Internal displacements are nowadays the largest and most dynamic category of forced migration. The global scale of internal displacement highly exceeds the current dynamics of international forced migration. Specialists in this subject emphasize the very diverse character of its causes and consequences. Factors influencing internal displacements can be virtually everything from international armed conflict and local escalation of violence, wildfire and earthquakegenerated tsunamis, to mining, urbanization, dam building and conservation of nature. However, all categories of displacement worldwide are associated with the occurrence of major conflict within a specific territory. Conflicts of this kind can have both a literal character (the escalation of armed violence) as well as a more indirect and implicit character (a conflict between the interests of the majority of society and the situation of internally displaced communities as a result of economic development, or the clash between humans and destructive forces of nature influencing future displacement). The causes of displacement are therefore dynamic conflicts of interest taking place between different categories of entities within a static and limited territory. The main factor of displacement is the impossibility of resolving the conflicting interests within the static territory. Such antagonisms are usually associated with a conflict over access to limited resources. Control over a defined territory, therefore, does not become an end in itself but only a tool with which to obtain control over particularly valuable resources.

The cause of displacement related to the escalation of violence is the conflict between at least two players for control over a particular territory. Underlying the displacement caused by repression and discrimination are past ethnic and religious antagonisms. The conflict is also a cause of disaster-induced displacement. The territory is in fact the arena of specific conflict between man and the destructive impact of the forces of nature. Resettlement associated with long-term environmental changes can also be placed in the category of conflict. It is associated with the inability to reconcile the previous mode of functioning with deteriorating living conditions and diminishing resources. The conflict between the sudden drop in resources and the need for existential and human adaptation measures is the cause of displacement due to famine. Long-term changes in the environment lead to a slow decline in the level of all the major categories of human security. A long-term disaster occurring in highly populated territory is often characterized by more precipitous dynamics and the forced sudden displacement of several thousand people. The root cause of development-induced displacement can be a conflict between the collective interests of a particular group of people and the existential needs of affected (PAPs) or displaced (DPs) people. Displacements of a similar nature have been observed widely in Africa and Asia in connection with nature conservation (the phenomenon of so-called conservation refugees). The desire to obtain control over certain resources or territory needed for transport becomes a common cause of displacement due to mining and oil exploitation. In the following passages I shall discuss each of the above-mentioned reasons for displacement and resettlement.

Before going into more advanced considerations it is worth emphasizing the difference between the categories of displacement and resettlement. These concepts in the literature often appear together and in the case of some specific processes (e.g. development-induced displacement and resettlement-DIDR) are even treated as stages of a single process of social change. To meet the requirements of scientific accuracy it should be noted that they are not the same process. Displacement is often defined as the single and irreversible removal of a person or entire community to a place outside the former homeland. Displacement can be either a single phenomenon or only a part of a more complex, multi-step migration process. We can speak of displacement as a single phenomenon where a specific injunction forces a person or a whole community to leave the territory, without definite plans for relocation elsewhere. Displacement of a population from its former homeland without previously established resettlement plans, adequate financial compensation, and social support mechanisms provided in the new place of residence, 
should be considered a human rights violation and completely prohibited. As examples of such activities we can mention, at a minimum, forced population displacement during the initial stages of armed conflict. Involuntary departure from the arena of war is not accompanied by any humanitarian assistance from the actors in the conflict. Further examples of this kind of displacement may be found in the displacement of population and lack of support during the first stage of a natural disaster, or displacement of people from an area of planned investment, unaccompanied by appropriate methods of assistance and social support mechanisms to be introduced later. The situation of people internally displaced during the initial stages of disasters is similar to the problems of people forced to flee their homes in the initial phase of the escalation of internal armed conflicts. Another example that can assist understanding of the concept is the nineteenth-century exile of Polish citizens to Siberia during partitions of Poland. Although the people were transported by the imperial Russian administration to the resettlement location, they very often received no support there.

Displacement may not only consist of a single act but can also be an initial step in a longterm process of resettlement, or a factor (known as a push-factor) generating other categories of forced migration, including that of refugees. Very often, leaving the current place of residence (displacement sensu stricto) is only the first stage in the process of resettlement. This happens when the displacement is accompanied by resettlement plans for the population in the other place, plans which should complement further social support for them. According to Robert Chambers "resettlement is characterized by two main features: A movement of population; and an element of planning and control" ${ }^{1}$. Resettlement arranged on the basis of prior agreement with the affected people, together with detailed plans which provide adequate compensation for the loss of goods, and future social support mechanisms, is not only acceptable, but very often helps to improve the economic conditions of affected and displaced communities. Displacement can be both an autonomous and therefore negative phenomenon as well as an element in processes such as resettlement, transfer or repatriation. Economic development and displacement associated with this process can sometimes even act as a push-factor in transnational population flows, including those of refugees and economic migrants. We can mention here at least two examples - the migration of Pakistani people to Brighton associated with previous displacement by the construction of Mangla Dam, and the flight of Chakma people from Bangladesh to India associated with the Kaptai Dam construction in Bangladesh.

The above-mentioned understanding of the category of "resettlement" is thus as a previously scheduled and multi-level process, accompanied by adequate compensation and social support mechanisms for the displaced. The category of development-induced displacement and resettlement (DIDR), often analyzed in recent publications, is therefore a two-step process. Physical preplanning for leaving the former place of residence is accompanied by adequate financial compensation and further means of social support for displaced persons (DPs) and project affected people (PAPs).

Forced migrations related to the sudden or gradual deterioration of environmental conditions can take place in varying stages. Displacement caused by the sudden impact of environmental hazards (disaster-induced displacement) is often associated with a short-term evacuation followed by a return to the same territory a few days later. Very often a short-term evacuation is undertaken because of the difficulty of determining the hazard's global dynamics. Displacement associated with slow-onset and more irreversible environmental transformations usually have a more long-term character. Desertification, soil degradation or water shortages may force people to move to another place permanently. One environmental phenomenon with a particularly high potential for long-term or permanent displacement or even international migration is the rise in ocean levels. However, this problem seems to be a matter for the very distant future. Displacements caused by economic development, long-term armed conflicts or irreversible climatic change are therefore much more

1 R. Chambers, Settlement schemes in Tropical Africa: A study of organizations and development, Praeger, London, 1969. 
permanent than those associated with natural disasters ${ }^{2}$. They are also very different if we take into account the motivations of people forced to flee their homes. In the case of disaster-induced displacement, the primary goal is to quickly leave the place of a strong threat to human security, without any strategic plans for the future. The goal of people fleeing from places affected by natural disasters is therefore to maximize the level of human security in the short term. By contrast, forced displacement caused by long-term environmental changes is part of an adaptive strategy, accompanied by long-term plans for the future. Such long-term environmental migrants are primarily interested in long-lasting or permanent maximization of the several categories of human security, which has been reduced as a result of a particular environmental disruption.

The best-known category of internal displacement is that associated with the escalation of violence, internal armed conflicts or discrimination against particular groups of people (mostly national, ethnic or religious minorities). I am thinking particularly of the consequences of wars, internal conflicts or acute local escalations of violence. The push-factor in these displacements can be either the actions or omissions of state and non-state actors. In Africa the problem of conflictinduced displacement is often associated with the fall of the state (e.g. Somalia, Democratic Republic of Congo). Some local conflicts in the developing world are associated with initial displacement on a large scale, but their short duration makes it very hard to estimate the number of displaced people accurately. Here the displaced people may return to their previously inhabited territories within a few months of the outbreak of the conflict. Due to the rapid dynamics of internal conflicts, the annual scale of this problem is difficult to assess correctly. According to the recently published IDMC report on conflict-induced displacement, there were 3.5 million newly displaced people in $2011^{3}$. For a few years, the global scale of the problem remained at the level of 24-27 million people. A particularly well-publicized example of the problem has been the internal displacement associated with recent crimes against humanity in Syria.

A large proportion of conflict-induced displacement of population worldwide, however, is long-term in nature. A good example of long-term internal displacement caused by armed conflict is the IDP population in Colombia. According to official estimates from December 2012, Colombia has a population of over 4.9 million people displaced by the long-term consequences of the civil war. CODHES estimations from December 2011 mention 5.454 million people internally displaced in that country. Other countries with long-standing and unresolved problems of conflict-induced internal displacement include Iraq, Azerbaijan, Cyprus, Burma, Somalia and Turkey.

The main reason for this category of displacement is the struggle for political power over a given territory. In the case of long-term escalation of violence, armed conflicts often lead to atomization and even the collapse of the state. The most basic conflict, of course, is between the oppressive aggressor and the people forced to leave their homes. In the case of conflicts in failed states or countries with significant separatist movements or strong ethnic antagonisms, the internal resettlement process may involve a far greater number of actors. The quest for power over a given territory is rarely a single cause of displacement. Frequently it is only an excuse for freedom of action within a specific territory and use of its resources. Ideological factors, too, are usually just an excuse for war over space and resources, along with the resulting forced displacement of the population. We can mention here the violent population displacements in Sudan related to the control of the territory of the constructed pipeline (the so-called Block $5 \mathrm{~A})^{4}$.

Many cases of internal displacement worldwide are not associated with the escalation of armed violence. Their common cause is discrimination, repression or victimization of one community by another. The consequence of organized discrimination can be the displacement of entire groups of minorities to remote areas. In the absence of armed conflict and strong

2 With the exception of the disasters that lead to the total destruction or contamination of a large territory, such as consequences of earthquake-generated tsunamis or irreversible chemical contamination.

3 Internal Displacement Global Overview 2011: People internally displaced by conflict and violence, IDMC, April 2012.

4

B. Terminski, Oil-induced displacement and resettlement. Social problem and human rights issue, Research Paper, Simon Fraser University, School for International Studies, March 2012, 18 pp. 
governmental rule over territory, displacement usually takes the form of deportation. Deportation policy is used especially in authoritarian or totalitarian countries with a centralized governance model as a means of weakening hostile communities. Its purposes are: 1. Achieving certain economic and political goals (e.g. acquisition of land with rich resources, provision of living space for the dominant racial group), 2. Tightening control over a defined territory through its political unification (displacement of communities can be here understood as a tool to increase the level of security in a particular area), 3. Breakdown of existing community cohesion, which may be a prelude to the group's marginalization and even physical extermination (breaking the existing links between people and the land inhabited by them for generations), 4. In some cases, deportation as a tool for the punishment, as well as physical extermination, of specific groups by hostile authorities. In this category is resettlement for forced labor.

According to reports from the Internal Displacement Monitoring Centre (IDMC), displacements caused by natural disasters (so-called disaster-induced displacement) form the biggest and most dynamic category of internal displacement. More than 42 million people were relocated in 2010, 14,9 million in 2011 and 32,4 million in 2012 following natural disasters, mostly atmospheric events such as floods, cyclones and hurricanes. According to the latest IDMC report 98 $\%$ of all natural hazard-induced displacements in 2012 was related to climate and weather related events. A much rarer cause of internal displacement worldwide is the natural disasters caused by geophysical events such as volcanic eruptions or earthquakes. The scale of disaster-induced displacement, and the security threats they represent, fairly outweigh the factors underlying development-caused displacement ${ }^{5}$. Humanitarian problems caused by natural disasters makes this category, together with conflict-induced displacement, the only category of displacement which is an object of concern to $\mathrm{UNHCR}^{6}$. It is worth mentioning that UNHCR humanitarian activity is generally limited to the particularly dynamic categories of internal displacement, which are usually associated with more spontaneous humanitarian threats and higher levels of human rights violations (conflict-induced displacement and disaster-induced displacement). The beginning of UNHCR activity in these specific categories of IDP protection can be traced back to the early and mid seventies. Categories of internal displacement characterized by much slower dynamics and less important humanitarian threats, such as development-induced displacement and environmentallyinduced displacement, are still not reflected in the analysis or the practical activity undertaken by the UNHCR. This agency clearly avoids the problem of development-caused displacement, which in turn plays an important role within the framework of activities of the World Bank Group. Only research-oriented institutions associated with the UN system (IOM, UNU-EHS) pay attention to the internal displacements associated with long-term environmental transformations.

The main factor in displacement is the sudden and strong emergence of a security risk factor preventing further stay in a particular territory. But we must remember that the scale of displacement depends not only on the strength of natural factors (e.g. floods) but also on subsequent actions undertaken by the authorities. Displacement can be generated either by spontaneous disaster or industrial accident and the associated evacuation that follows. The main push-factor in disasterinduced displacement is thus a security threat, but it is usually driven by state authorities in the form of evacuation. Displacement associated with long-term climate change is controlled by state authorities to a much smaller extent. The territory thus becomes an arena of conflict between human activity and the forces of nature. The category of "environmentally-induced displacement" can be viewed in two different ways. In a broad sense it covers all the environmental factors influencing the dynamics of forced internal mobility. In its narrower meaning, the term refers only to the displacement (forced migration) caused by long-term environmental changes such as desertification of soils, drought, the long-term consequences of soil degradation, and rising sea levels. This analysis is based on the narrow form of the problem. Dynamic nature and the significant scale of

5 However, DIDR is of more permanent nature than displacement associated with natural hazards.

6

B. Terminski, Environmentally-induced displacement. Theoretical frameworks and current challenges, University of Liège, 2012. 
disaster-induced displacement are here understood in opposition to the slower onset of environmentally-induced displacement. The approach to the problem that is presented here therefore differs significantly from another of my theoretical approaches to this problem (B. Terminski, Environmentally-Induced Displacement. Theoretical Frameworks and Current Challenges, Université de Liège, 2012).

Disaster-induced displacement is comparable to the rapid and indiscriminate action involved in leaving the danger zone without well-defined plans for the future. Often it is of a very short-term nature, such as the evacuation within several hours associated with the threat of flooding or tsunami waves in coastal areas. Environmentally-induced displacement is one of the adaptation strategies implemented in response to more long-term and irreversibly deteriorating living conditions in a particular territory and the declining level of human security associated with this process. The category of environmentally-induced displacement is usually associated with a lower level of security threat than disaster-induced displacement. The rationalization of migration strategies which characterized many cases of environmentally-induced displacement makes it sometimes difficult to distinguish them from environmentally conditioned economic migration. Let me direct attention to at least three cases in which the environmental context of forced migration was strongly associated with its economic aspect. According to some sources, desertification of soils in Brazil, observed in the mid-seventies of the last century, forced rural-urban migration of several million people, especially young men. As we know, long-term environmental changes (especially soil degradation) very often force the migration of entire communities and their subsequent impoverishment in urban centers. Another example of the interaction of environmental and economic factors is the so-called independent child migration from the north rural areas of Ghana in the direction of the coastal cities, especially the capital of the country, Dhaka. Migration of children in Ghana is an example of phenomena in which economic and environmental incentives contribute significantly to forced migration. Currently observed, or even potential, environmental changes are an additional factor influencing international migrations. We can mention the growing scale of immigration of the inhabitants of Tuvalu archipelago, which is vulnerable to potentially rising sea levels in future, to neighboring countries such as New Zealand. According to some sources, nearly 3,000 people, or 25 percent of this archipelago population, have already left Tuvalu. Here too it is very difficult to separate environmental and economic factors in migration. The task is much easier in the case of the migration of Mongolian pastoral tribes, affected by desertification of soils, to the poor suburbs of the capital city, Ulan Bator. In this case, environmental factors are the basic push-factor of displacement, enforcing changes in social, economic and cultural modes of existence.

At least fifteen million people each year are forced to leave their former places of residence following the actualization of big development projects (M.M. Cernea, A. Oliver-Smith, B. Terminski). The category of development-induced displacement is based on the identification of particular territory as a source of economic profit. Often, however, the aims of the government, private business and the public are, for the most part, opposed to the interests of the people forced to flee their homes. Territory becomes an arena of brutal conflict of interest, the victims often comprising the most vulnerable categories of people such as indigenous people, rural communities, women and children. Their limited ability to adapt to conditions in the other territory often causes their attempts to settle there to fail. Leaving the place of current residence leads to the erosion of all individual and community pillars of human security. Among the most negative consequences of development-induced displacement, Michael Cernea has mentioned: landlessness, joblessness, homelessness, marginalization, food insecurity, loss of access to common property resources, increased morbidity and mortality, and community disarticulation. An interesting element of the IRR model is its consideration of the impoverishment and other problems of host communities. The 1982 model of Elizabeth Colson and Thayer Scudder (known as the Colson-Scudder four stages model) outlines four stages of resettlement: recruitment, transition, development, and incorporation/handing over? 
According to Michael M. Cernea and Anthony Oliver-Smith, each year economic development leads to the displacement of at least 15 million people worldwide. The largest scale of internal displacement following development projects is found in the two most populous countries: China and India. The major causes of this problem include:

- Creation of dams, artificial reservoirs, hydropower plants and irrigation projects. Projects of this kind have for a long time been the greatest cause of development-induced displacement and resettlement (DIDR). According to the World Commission on Dams (2000) construction of large dams has displaced between 40-80 milion people worldwide. Even in 2000 it was considered to be the cause of more than 26 per cent of developmentinduced displacement in the world. The most controversial projects completed in recent years include the construction of the Three Gorges Dam in China and the Sardar Sarovar project on the Narmada river in India. The most controversial examples of displacement caused by dam building include those from China and India. At least 1.26 million people were displaced from their neighbourhoods following the construction of the Three Gorges dam on the Yangtze river. The most famous examples from India include the construction of Sardar Sarovar Dam (340 thousand displaced people), the Hirakud Dam, the Pong Dam and the Tehri Dam.

- Development of communication networks: the construction of roads, highways, railway, bridges, airports, port districts, etc. We can mention here, for example, construction of the Jamuna and Padma bridges in Bangladesh, construction of the A1 freeway in Mozambique, railway development in Cambodia, and the construction of the highway system in Boston (the so-called Big Dig).

- Urbanization and urban transformation. Among the processes leading to the greatest amount of resettlement we can mention: 1. Housing units reconstruction following war damage, 2. expansion of urban areas, 3. Transformation of urban space (for example, demolition of poverty clusters such as slums and favelas in Latin America), 4. Water supply, and 5. Subway construction. We can mention here the World Bank-funded resettlement of the Madagascar urban population in Antanarivo Plain. Among other urban projects associated with the largest scale of displacement we can mention Indonesia's Jabotabek project, which displaced approximately 40,000-50,000 people, and India's Hyderbad Water Supply Project, which ousted 50,000 people $^{8}$. According to Agarwal Mumbai Urban Transport Project (MUTP) involved resettlement of about 100,000 people 9 .

- Deforestation and the expansion of agricultural areas. The felling of trees often precedes the establishment of large monoculture plantations. We can mention the jungle clearances in Borneo, the trees being replaced with palm oil plantations, as happened during the eighties and nineties. Practices of this kind are not only a major threat to biodiversity and source of environmental degradation but also lead to the displacement of an increasing number of people throughout the world.

- Mining and oil exploitation. Expansion of open-pit mining leads not only to an increasing number of displacements but also to contamination of water, soil and air. The most discussed examples of this problem are gold mining in Ghana and Mali (Tarkwa and Sadiola regions), coal mining in the Jharkhand region of India, and the planned Phulbari open-pit mine in Bangladesh. Resettlement caused by the development of mining has also been a highly visible problem in developed European countries such as Germany and Poland. The development of lignite mining in Germany during the twentieth century was the direct cause of the resettlement of between 30 and 100 thousand citizens of that country. Copper mines on the island of Papua also led to resettlement on a significant scale. As noted by Walter

voluntary resettlement.

8 J. Stanley, "FMO Research guide: development induced displacement and resettlement", Refugee Studies Centre, 2000 .

9 A. Agarwal, "Mumbai Urban Transport Project - A multi dimensional approach to improve urban transport", Research in Transportation Economics, Vol. 40, Issue 1,April 20113, pp.116-123. 
Fernandes, in the Jharkhand region alone, mining has caused the displacement of 2.55 million people over the last fifty to sixty years. In recent years we have seen a significant increase in the scale of so-called mining-induced displacement and resettlement (MIDR). The main reason for this process is the considerable increase in the size of mining areas. According to Walter Fernandes, the average size of coal mines in India has grown from 150 acres in the 1960s to 800 acres in the 1980s (Fernandes, 2007). Extraction of raw materials is very often carried out by transnational corporations based in other parts of the world. Gains from the extraction of raw materials, therefore, do not contribute to the development of the country's economic output, let alone to improvement in the situation of displaced people. The automated extraction method in current use also denies most displaced people the chance to work in the mining industry. But despite this negative image of the consequences of mining, we can mention at least a few positive examples. With appropriate financial compensation and well-planned resettlement, mining does not have to amount to the exploitation of resources in the third world, but can rather be a means of reducing disparities and promoting the well-being of local communities.

- Another frequent cause of displacement is the extraction and transportation of crude oil and gas (the problem of so-called oil-induced displacement and resettlement). Exploitation and transportation of crude oil requires strong control over the territory. Fearing for the safety of pipelines, authorities have often displaced population from the pipelines' neighborhood. The construction of a nearly 1,500 km-long pipeline in Sudan, launched in 1999, led to the displacement of over 100,000 people (World Food Program and Operation Lifeline Sudan give the figure of 174,000 displaced people). Also in Nigeria, oil production has been associated with negative involvement of international capital and the persecution of local communities. Since the early nineties we have observed in this country growing tensions between transnational corporations and an authoritarian regime, on one side, and the deteriorating environmental conditions of the Ogoni and Ijaw tribes on the other. It is estimated that military repression of the people of the Niger Delta has led to the death of hundreds of people (including environmental activist Ken Saro Wiwa) and the internal displacement of tens of thousands afterwards. Construction of the Yetagun and Yadana gas pipelines in Burma was accompanied by severe repression of the surrounding community by the authoritarian junta ruling that country. A limited scale of displacement from pipeline areas was accompanied by various human rights abuses, including forced labour. The social consequences of resource extraction in Nigeria, Sudan and Burma were characterized by a number of common elements. These include: 1. mass displacement in order to protect the pipeline zone, 2. financial participation of transnational corporations in the construction of pipelines or mining of raw materials, 3. the authoritarian model of governance characterizing all countries burdened with the problem of oil-induced displacement, 4. strong ethnic antagonisms and displacement of communities targeted by the central government.

- Conservation of nature. Displacement caused by the creation of conservation zones is often analyzed as one of the social consequences of economic development. It should be noted, however, that the conservation of nature differs significantly from other causes of development-induced displacement and resettlement (DIDR). It therefore seems essential to consider nature conservation as a separate cause of internal displacement. In India and many African countries, this category of displacement occurs on such a scale as to inspire comment on "conservation refugees", defined as "people, usually indigenous, who are displaced from their native lands when conservation areas are created, such as parks and other protected areas". The main cause of this problem is the creation and expansion of national parks and other conservation areas. Unfortunately, in many cases, this is combined with the cutting down of trees and the aspirations of the business sector to take over the areas possessing desired resources, such as diamonds. Deprived of existing habitats, indigenous people have limited capacity to adapt to a new place of residence. Often their 
only solution is to return, illegally, to their former lands, from which they are mostly banned by the local authorities. It is estimated that conservation of nature has so far caused the displacement of tens of millions of people worldwide. In Africa alone, Charles Geisler estimates the number at 14 million people forced to leave their habitual homelands following the introduction of nature conservation projects. In India, the problem in recent years has affected 1.6 million people, which could rise to 2-3 million in the next decade. The best known examples of conservation-induced displacement includes these associated with the creation of Serengeti National Park in Tanzania (50,000 displaced people) and Kibale National Park in Uganda (30,000-35,000 forcibly removed people).

The last cause of internal displacement is a specific combination of many factors. I am thinking in particular of the displacement caused by hunger and specific categories of displacement in urban areas such as evictions. The cause of hunger is a significant decrease in resources, leading to an imbalance between existential needs and opportunities to meet them. Famine, however, is rarely a consequence of only one deteriorating factor The negative impact of one factor is usually accompanied by a vicious act or omission on the part of the government. A common cause of hunger, for example, is a combination of natural disaster, the collapse of agricultural production from prolonged drought, and political errors in the management of food or the weakening power of the state ${ }^{10}$. The concept of famine as a phenomenon arising from a combination of environmental, economic and political factors is presented inter alia in Amartya Sen's famous book Poverty and Famines: An Essay on Entitlements and Deprivation (Oxford, Clarendon Press, 1982). In his opinion, the cause of famine in Bangladesh in the years 1973-1977 was a combination of the consequences of floods, errors in the distribution of food, and the political instability of this newly created state. However, we can mention many examples of famine caused by the strong influence of a single factor. The main cause of disaster in Ukraine in 1932-1933 was the wrongful policy of forced collectivization, which has nothing to do with natural disasters or crop failures.

Famine is usually a long-lasting process and migration should be treated as one of its adaptation strategies. The problem of hunger in rural areas is often accompanied by mass migration to the cities. Given the rapid increase in urban population and limited food resources, it is not always a good solution. In the case of famine in some Sahelian countries, the forced migration solution proved to be one of the least effective adaptation strategies taken up in order to survive.

Displacement caused by transformation of urban space is increasingly analyzed in the literature on the problem. I am thinking in particular of evictions related to economic problems and poverty clusters demolition ${ }^{11}$. They are often part of a policy of discrimination against the poorest social strata. The problem in many developing states even includes elimination of IDP camps and displacement of people residing there.

The vast majority of contemporary classifications of internal displacement are centered on analysis of its causes. The predominant method of classification distinguishes four categories of internal displacement: conflict-induced displacement, environmentally-induced displacement, disaster-induced displacement and development-induced displacement. Very broadly, however, this classification gives a picture of the mixed nature of the process worldwide. Thus we can see a growing number of specific categories, such as "mining-induced displacement and resettlement", "hydropower-induced displacement" or "nuclear refugees" and "conservation refugees".

Taking the above-mentioned considerations into account, it seems most appropriate to distinguish seven main causes of internal displacement worldwide. These include:

1. Wars, internal conflicts and local escalation of violence. The actors responsible for generating

10 The most important causes of famine (and famine-induced displacement) include: 1 . war and conflicts, 2 . weather and climate change, 3. incorrect argicultural practices, 4. consequences of the incorrect economic policies, 5. population growth, 6 . poverty.

11 A good example of such problems is Operation Murambatsvina in Zimbabwe, government campaign to forcibly clear slum areas across the country. The campaign started in 2005 and according to United Nations estimates has affected at least 700,000 people directly through loss of their home or livelihood and thus could have indirectly affected around 2.4 million people. 
displacements are both state and non-state actors, associated with a sharp decline in individual security. Because of a threat to the most fundamental elements of human functioning, this category of displacement attracts the most attention from intergovernmental actors and humanitarian agencies (such as ICRC, UNHCR, etc.).

2. Persecution, discrimination and repression which are not associated with internal armed conflicts or escalation of violence. Among the various forms of this type of displacement we can mention deportation of entire communities to the periphery, deportation to forced labor, and many other practices.

3. A negative change in living conditions caused by long-term environmental changes and disruptions. Among the reasons for this category of displacement are: desertification, shoreline erosion, sea level rise, and prolonged drought. Migrations of this type are much more rational adaptive processes than the spontaneous and often short-term evacuation caused by natural disasters. Environmentally-induced displacement can be regarded as an adaptive strategy following decline of the human security level to a point below the threshold of sustained normal existence within a particular area. Environmentally-induced displacement is therefore a response to long-term problems in a situation of irreversible depletion of means of adaptation.

4. Natural disasters and man-made industrial accidents. Displacement in the aftermath of such events may consist of brief temporary evacuation as well as prolonged displacement, as seen in the consequences of the Asian tsunami of December 2004. Displacement is not a choice or an adaptation strategy but the only possible strategy for avoiding potential risks. The primary consequence of natural disasters is the spontanous and very strong decrease in individual security, which is quite similar to the first phase of internal conflicts. In countries such as Sudan this category is strongly connected to overall political tensions.

5. Consequences of economic development and implementation of big projects. These have the strongest effects in countries characterized by intense antagonisms between authorities and indigenous populations or other minorities.

6. Conservation of nature. Protection of nature is a result of the negative consequences of economic development. We can understand the problem of "conservation refugees" as part of the general context of development-induced displacement and resettlement.

7. The specific combination of political, economic and environmental problems such as famineinduced displacement.

The above-mentioned classification does not exhaust all the theoretical views. Further classifications can provide a response to the problems through clear separation of the causes of internal displacement. The following classifications are mere drafts and should not be understood as providing a point of reference for more advanced theoretical considerations.

The first working classification is based on: a) scale and degree of reversibility of the risks affecting the displaced, b) analysis of the spontaneous or more prepared character of forced mobility, c) individual motivations of the displaced people. Based on the above elements we can distinguish two main categories of forced displacement worldwide: displacement of risk and displacement of adaptation.

Displacement of risk/insecurity displacement. Here the primary goal of displaced people is to leave the dangerous area as soon as possible without any specific plans to settle elsewhere. The cause of this type of displacement is a sudden reduction in the level of individual or community human security as a result of the impact of certain factors (flood, tsunami, industrial accident, civil war). An example of this type of short-term resettlement is an evacuation due to wildfire or flood. Among the examples of long-lasting displacements of this kind we can mention the consequences of the Asian tsunami and conflict-induced displacement in Sudan.

Among the root elements of this category of internal displacement we can mention: frequent lack of choice as to whether to stay in the dangerous territory, the strong impact of the risk factor, and the inability to adapt to change. The main goal of the displaced person is not to settle elsewhere but to escape quickly from the territory affected by security risks in order to avoid potential threats. The sources of this category of displacement are dynamic phenomena that leave little opportunity to 
adapt. These include: international and internal armed conflicts making it necessary to leave the combat zone, the sudden escalation of local violence, natural disasters such as earthquakes or volcanic eruptions, industrial accidents, forced deportations without guaranteed social support, etc. There is also very often a decision by affected people to leave the danger zone in advance of further evacuation carried out by state authorities or humanitarian aid agencies.

Displacement of adaptation/adaptive displacement. In this case, leaving the current place of residence is not the main goal but only part of the process of improving living conditions or seeking future support elsewhere. It is often a result of a pre-planned decision and comparatively weak long-term risks to human security. Adaptive displacements are mainly associated with longterm environmental changes and long-lasting conflicts with weak dynamics.

Examples of this process include displacements as a result of the long-term impact of specific problems (environmentally-induced displacement), and those which are accompanied by support from institutionalized centers of power (for example, population transfers in Europe after the Second World War). They include: development-induced displacement, repatriation, population transfers carried out by the state, population redistribution schemes, and displacement as a result of long-term changes in the environment (e.g. desertification).

The classification I suggest here is of course not totally new in the scientific literature. Some of its elements were already pointed out by Astri Suhrke in 1993, in a very interesting article entitled "Pressure Points: Environmental Degradation, Migration and Conflict". Suhrke divided into two categories people forced to leave their lands following environmental degradation. Participants in spatial mobility caused by environmental degradation were divided into environmental migrants and environmental refugees. As Suhrke noted, environmental refugees are persons displaced as a result of the impact of extreme environmental degradation. Environmental migrants are persons changing residence before the expected problems arise. According to Astri Suhrke, for environmental migrants, "migration is part of the solution rather than the problem. For the environmental refugee, by contrast, movement itself is fundamentally the problem" 12 . In the same article Suhrke points out that environmental degradation can contribute both to the forced displacement of many thousands of people from their current place of residence as well as to the growing scale of voluntary economic migration to the same area. Establishment of an industrial center is very often associated with the problem of development-induced displacement. Later observed deterioration of environmental conditions in the immediate vicinity may cause a new wave of displacement (environmentally-induced displacement). At the same time, however, the development of industrial areas is a growth factor (pull-factor) of voluntary economic migration. New housing units established for industrial centers can cause the number of migrant workers who come to this area to surpass the number of people displaced as a result of the negative consequences of their formation (positive net migration).

The next classification criterion is based on the impact of a change of residence on the evolution of the economic model, social ties and cultural identity. Taking into account the abovementioned factors we can distinguish two general categories: microdisplacement and macrodisplacement. By the prefixes "micro" and "macro" I do not refer to the spatial distance between the former area of residence and the new home; for indigenous migration to the city suburbs just a few miles away may be associated with much bigger problems (in the context of evolution of cultural, economic and social models of life) than displacement to a territory distant from the abandoned area by as much as two hundred kilometers. Much greater is the difference between old and new models of existence in terms of difficulty of adaptation for communities characterized by limited adaptive capacity. The distance between the new place of residence and the old is not the basic factor determining the changes induced by resettlement.

Microdisplacement is a change of residence characterized by limited social, economic or

12

A. Suhrke, Pressure Points: Environmental Degradation, Migration and Conflict, Christian Michelsen Institute-

American Academy of Arts and Sciences, 1993. 
cultural consequences. Resettlement does not lead to irreversible change in social relations or the need for far-reaching cultural adaptation. It does not lead to the atomization of local communities. Its consequence is primarily mobility across areas relatively similar to the abandoned territory.

Macrodisplacement. This category of displacement takes place when even a close spatial movement is accompanied by changes of key importance to human existence. As an example of this phenomenon we can mention resettlement of rural communities or of specific labor categories in cities associated with the construction of the Three Gorges Dam. Similar consequences were observed when environmental displacees from the island of Bhola were resettled into the suburbs of Dhaka, the capital of Bangladesh.

\section{Environmentally-Induced Displacement: Some Historical Reflections}

Migrations over the centuries are primarily a history of human emancipation from the dictates of the forces of nature along with the increasing adaptation of biological and social skills to make possible the colonization of hostile areas. Long-term changes in the environment have been the most important reasons for human mobility throughout history. Biological evolution, accompanied by the development of tool production and hunting techniques and the formation of protolanguage, were the root conditions which allowed the early Homo species to undertake distant migrations. However, we must note that the expansion of homo georgicus, homo erectus and homo sapiens sapiens out of the African cradle of man would not have been possible without favorable environmental conditions. According to the so-called Saharan Pump Theory, the greatest proportion of migration in Africa took place by designated routes along rivers and lakes. Consequently, the dry period closed the earliest migration corridors for many thousands of years, successfully preventing the earliest migrations of Homo in Africa and beyond.

The Neolithic (r)evolution led to greater diversity than ever before in the causes of displacement and migration. The search for favorable land for agriculture and grazing resulted in migration processes that were much more thoroughly planned than previously. The first large settlements such as Catal Huyuk and Jericho were planned and established in areas with suitable living conditions. Already during the sixth and fifth millenniums $\mathrm{BC}$ we can observe causes of voluntary migration by agricultural communities in search of more favorable land and conditions of existence. During the subsequent centuries we witness the first advanced attempts to regulate the destructive forces of nature by establishing settlements in the estuaries, together with the first irrigation projects. Such actions have been among the causes of social organization and of the emergence of politics.

The earliest resettlements were strongly affected by progressive environmental changes and declining resources. When resources shrank below the minimal level required for existence, the only solution was to relocate elsewhere. Sudden disasters such as drought, floods or famine led to a strong decline in population rather than migration with the aim of adaptation elsewhere. Low levels of technical development combined with location of human settlements in the basins of great rivers made it difficult for the group to move to another location in the event of a spontaneous natural disaster such as flood, drought or famine. Floods were usually associated with the complete destruction of urban settlements, leading to their total collapse.

After antiquity, environmentally-induced displacement very clearly influenced political change, pre-empting even the fall of empires. Shrinking resources created massive displacement and associated pushing of neighboring communities to more distant areas. Therefore we can consider the Sea Peoples and Huns to be both invaders and environmentally-induced displaced people ("environmental refugees"). We can speak of a kind of environmentally-caused migratory domino effect - migrations generated by environmental changes which finally led to changes in the political and ethnic maps and even to the fall of ancient Rome. Within the category of "environmentally-caused migratory domino effect" we can explain the invasion of the Huns and Germanic tribes pushing toward the borders of the Roman Empire. Soil desertification was one of the root causes of the thirteenth century Mongol invasion of Europe. Like the Huns ten centuries 
earlier, the mobile and well armed Mongolian peoples should be recognized as both aggressors and environmentally-induced displaced people.

Static boundaries and climate stabilization reduced the importance of environmental displacement in Europe. However, environmental factors continue to play a very significant role in migratory patterns, especially in the regions recently affected by the consequences of the Neolithic revolution, where environmental disruptions were frequently observed. Currently, over $95 \%$ of all environmentally-induced displacement is taking place in the developing countries. But remember that the migrations caused by long-term environmental changes occur even in the most developed nations. The consequences of the American Dust Bowl in the thirties provide a good example of migration caused by a combination of environmental and economic factors. Even natural disasters are becoming a more serious social problem in developed countries. Here we can mention, at least, Hurricane Katrina, which displaced nearly 300 thousand US inhabitants.

\section{Environmentally-Induced Displacement as a Human Security Issue}

According to IDMC reports, natural disasters are the greatest and most dynamic cause of internal displacement in recent years. This does not mean that we can afford to marginalize displacement caused by long-term environmental changes. Incoming information about the growing scale of global warming is forcing us to look at the social context of long-term environmental hazards. The decline of resources caused by climate change may be a significant factor in internal and international conflicts and the mass displacement they cause. Already we see forecasts of socalled "climate wars" - armed conflicts resulting from alarming environmental changes - in the near future. Particularly vulnerable to this kind of conflict are the semi-arid and desert areas of Africa. The growing population in South Asia, in conjunction with the observed environmental problems there, could lead to similar conflicts over resources, possibly causing not only displacement but even boundary changes. It is already the case that the available resources in most of Africa are insufficient to meet the basic needs of its residents.

The impact of long-term environmental changes on the dynamics of forced mobility can thus be either direct or indirect. We can speak of direct impact when the climate change is a primary cause of displacement. Among examples of this kind of situation we can mention displacement as a result of shoreline erosion and rising sea levels or progressive desertification. However, displacement of a monocausal character, associated only with climate change, is extremely rare. Such displacement is most often associated with a negative impact on the economic situation. Climate change can often have a negative impact on economic production in a given area, leading in turn to forced migration.

The indirect impact occurs when the environmental changes produce a conflict over resources. A typical example was the expansion of Huns and Mongols into Europe, caused by the desertification of the steppes in Central Asia. Decline in resources becomes an existential reason for lowering the level of personal and community security. After exhausting other adaptive strategies to improve the situation, all the people can do is to expand into areas with more resources, entailing potential conflicts with its inhabitants. Among resources with particularly high potential for conflict we can mention water and agricultural land. An especially high risk of this kind of conflict is illustrated by the situation of poor African and Asian countries. Good soil and access to potable water can be a conflict factor comparable to valuable mineral resources. Population growth also contributes to some environmental problems such as deforestation and rising pollution. Let us mention here the exile from Haiti induced by deforestation, observed even at the turn of the nineties.

The main cause of the displacement, which is not based on administrative coercion but on the impact of threats, is the combination of sharp decline in personal or community security and the lack of opportunities to maximize it on-site. Long-term environmental changes can lead to the erosion of all categories of human security. Therefore, we cannot reduce further considerations to the categories of economic and political security. A useful tool for analysis is the classification of 
seven core areas of human security, presented in the Human Development Report, published by UNDP in 1994. The development of the concept of human security, dating back to the early and mid nineties, was related to the collapse of the bipolar international order and movement away from the perception of security in terms of military balance. Evolution of this area of study was also related to the concept of sustainable development introduced in the late eighties (Brundtland Report, 1987).

The UNDP Human Development Report distinguishes seven basic pillars of contemporary human security: economic security, food security, health security, environmental security, personal security, community security and political security. Taking into account the fundamental elements of human and social functioning, the above-mentioned classification seems a very appropriate research tool. However, for the purposes of the following analyses, it should be complemented with two additional categories: gender security and cultural security.

My analysis will be confined to the case of displacement directly linked with climate change, which includes: consequences of desertification, sea level rise and rising temperatures. But to a limited extent I shall refer to the security risks associated with man-made environmental problems: in particular to the strong dynamics of land degradation associated both with climate change and with the negative consequences of human activities.

The impact of long-term environmental changes on different areas of human security as a push-factor of forced migration is an issue prominently discussed in the literature. Among the most significant publications in this area we can mention the report entitled Human Security, Climate Change and Environmentally Induced Migration published in 2008 by the United Nations University (UNU-EHS). Among other publications it is worth mentioning an article by Jon Barnett and W. Neil Adger, called "Climate change, human security and violent conflict", published in Political Geography (Vol. 26, 2007).

Economic security - Climate change leads to economic threats on a vast scale. We must take into account that most climate change and over $90 \%$ of natural disasters affect developing countries, where the population is already weighed down by other economic problems. A particularly important consequence of desertification is decrease in agricultural production and the consequent decline in vital resources. Problems of this kind are nowadays highly visible in many places worldwide. Residents of Mongolia, for centuries engaged in pastoralism, are unable to feed their herds and are forced to move to the suburbs of Ulan Bator. The consequence of this migration is not only further economic marginalization but also a drastic change in the model of social relations and erosion of cultural heritage and social ties. Soil desertification in Brazil, observed in the mid seventies, has forced several million people to migrate from rural areas to the cities. These desertification-induced migrations were undertaken mostly by young men. Rural-urban migration also became a major problem in Africa during the Sahelian drought in the seventies and eighties. Response to the decline in agricultural production has produced different adaptation strategies. Among well-known strategies for adapting to climate change we can mention independent child migration from rural to urban areas, practised in Ghana, Burkina Faso, Vietnam and India. However, we must remember that migration from rural to urban areas is often not the best adaptation strategy in the case of progressive desertification or even famine.

Even a small-scale rise in global sea level may lead to unimaginable economic and social consequences. As pointed out by Koko Warner et al., coastal areas occupy only two percent of the globe. However, these areas are inhabited by as much as ten percent of the world's population and thirteen percent of its urban population. One country highly vulnerable to rising sea levels is Egypt, which at the same time is struggling with the increasing scale of desertification. In Vietnam, a sea level rise of just one meter could jeopardize the normal functioning of as much as ten percent of the population of this country. Areas of the world most vulnerable to the consequences of rising sea level include: the countries of Oceania, China, India, Vietnam, Bangladesh, Nigeria, Ghana, and even some European countries and the U.S. coast.

The best-known example of displacement caused by permanent flooding of the territory is the case of the former inhabitants of Bhola Island in Bangladesh. This problem was the result of 
long-time flooding rather than of displacement directly caused by the rising sea level. Even today, rising sea level is causing agricultural losses in some countries of Oceania, as salt water gets into the rivers and fields, destroying crops. Coastal erosion is also becoming more of a problem in several countries of continental Asia.

Food security - Climate change is one of the main factors contributing to the growing imbalance between the rate of food production in developing countries and in developed countries. According to the FAO document entitled "Climate Change and Food Security: A Framework Document", adopted in Rome in 2008, "Climate change will affect all four dimensions of food security: food availability, food accessibility, food utilization and food systems stability. [...] As an indirect effect, low-income people everywhere, but particularly in urban areas, will be at risk of food insecurity owing to loss of assets and lack of adequate insurance coverage. This may also lead to shifting vulnerabilities in both developing and developed countries. Food systems will also be affected through possible internal and international migration, resource-based conflicts and civil unrest triggered by climate change and its impacts."

In the situation of deteriorating climatic conditions, obtaining food becomes increasingly difficult and prices can rapidly rise. The struggle for food is set to generate more and more pathological phenomena. According to experts from the Norwegian Refugee Council (NRC), the 2008 food crisis in Bangladesh generated pathological phenomena such as prostitution and child labor. The consequence of lack of access to food becomes a negative social challenge in Bangladesh, India and most African countries. In the case of pastoralists living in Somalia, climate change and resulting desertification brings competition for resources and becomes a cause of conflict.

The rise in ocean temperature can be a threat to biodiversity. According to Jesse CameronGlickenhaus, the coral reef system is an important source of food supply for about a billion people worldwide. The destruction of coral reefs induced by climate change can become a substantial threat to food security, forcing many inhabitants of coastal regions to migrate to other territories. Jesse Cameron-Glickenhaus gives the archipelago of Palau as an example of this type of problem ${ }^{13}$.

Environmental security - As earlier noted, long-term environmental change has an impact on all categories of human security, without exception. It is worth paying attention to the more general dimension of this problem. In the era of postmodernism and globalization, friendly environmental conditions are seen as a resource and negative climate change as leading to its gradual decline. Preventing this process requires not only the actions of the international community but also a transformation in thinking on the part of us all. We need to build a network of environmentally sustainable societies that do not harm each other, leading to a balanced global environmental policy. The right to a good environment should not be seen as a privilege but as the duty of each of us. Nevertheless, in the last two decades we have seen at least a few states that could be called environmental aggressors. The cutting down of the Amazon jungle is not only an internal problem for Latin American countries but a challenge to the entire international community. It therefore appears necessary to raise the category of environmental justice to the level of a global imperative, having a strong correlation with the four concepts: human rights, human security, sustainable development and human development.

Health security - It is estimated that the consequences of climate change directly affect more than one billion inhabitants of our planet. An especially big problem seems to be the increased difficulty of access to drinking water and progressive degradation of agricultural and. According to estimates by international organizations, nearly two billion people have very limited access to potable water and appropriate sanitation. Lack, or inadequate quality, of drinking water is the cause not only of environmentally-induced displacement but also of a number of contagious diseases. Particularly vulnerable to health problems are women, children, indigenous people and the elderly. The greatest

13 J. Cameron-Glickenhaus, "Palau-coral reef protection", Forced Migration Review, Vol. 31, October 2008, pp. 52-53. 
threat in this context seems to be the problem of famine associated with declining resources. The level of health depends to a large extent on housing conditions, access to drinking water, agricultural land and community resources such as forests, rivers, pastures, etc.

Personal security - A significant decrease in personal security to a level below that needed to ensure the fulfilment of basic existential needs is the primary reason for most climate change displacement. Escalation of violence caused by environmental change can affect the most fundamental areas of human security. The best way to analyze the negative social consequences of climate change seems to be through the concept of human rights. The lack of basic resources and the escalation of violence caused by conflict over resources is a threat to the most fundamental human rights, including the right to life as well as civil and political rights. Lack of action to prevent climate change violates the right to development in many parts of the world and maximizes the asymmetry between human development in the "north" and the "south". Such inaction is therefore contrary to the right to human development, sustainable development and maximization of the welfare of all people.

Community security - The consequences of climate change are considered to be among the most irreversible collective causes of displacement. Their effects are largely independent of the human will, and extend to all residents of the area. Both desertification and rising sea levels pose a huge threat to the security of entire communities. Desertification in Africa over thousands of years forces communities living there to choose between forced migration or potentially bloody conflict over resources, and between attempts to find a rapid adaptation strategy or atomization and even physical extermination caused by famine. The impact of rising sea levels on community security is even greater. This entails an irreversible loss of the territory which constitutes a primary site of the formation of existing political ties as well as of economic, social and cultural relations. Taking into account the criterion of irreversibility, the consequences of climate change are similar to those seen in the general context of development-induced displacement.

Political security - Both natural disasters and long-term environmental changes may lead to huge political transformations. At the moment, a much more destabilizing factor is the sudden occurrence of natural disasters. The example of the earthquake in Haiti shows us that, in extreme cases, a great cataclysm can even lead to the collapse of the state. Long-term climate change has less potential for political destabilization today. Many of the consequences of climate change affect countries with a low level of political stability. The desertification observed in sub-Saharan Africa thus becomes another problem and conflict factor in already highly unstable countries. Significant potential for political change in the future may be caused by rising sea levels. Phenomena of this kind may lead to conflicts over space and a related wave of conflict-induced displaced people. The regions of the world where rising sea levels may become a particularly important political issue include highly populated countries in Africa and Asia: Nigeria, Bangladesh, India, China and the small countries of Oceania.

At present, a decidedly more important problem lies in the political conflicts caused by increasing environmental pressure. Progressive desertification may produce an environmentallycaused migratory domino effect. Communities fleeing climate change become invaders who deprive neighboring groups of resources and drive them to other territories (or peripheries). So far, the problems have been observed only on a microscale. The combination of increasing population growth, declining resources, and climate change may, however, lead to "climate wars" of internal or international character. Conflicts of this kind can lead to the disintegration or collapse of some countries, and even change the external borders in some regions of the world. Particularly vulnerable to these problems are the already marginalized groups such as women, children, indigenous people, rural communities, illegal settlers and several categories of minorities.

Negative climate change leads to a significant decrease in resources in a given space. Especially susceptible to these threats are groups already discriminated against for access to 
resources and having very limited economic flexibility. Limited ability to adapt quickly makes it impossible to maximize individual security and break out of the trap of nature. Considerable attention has been paid to the impact of climate change on the social, economic and industrial position of women. Desertification-induced migration from the countryside to cities often leads to a decline in the economic position of women, thus lowering their status in the family. Women who previously performed essential roles in the household now become much less productive economically. The lack of access to common resources such as land, pastures, and rivers means that they cannot carry out their previous economic activities (such as collecting firewood and growing food for the family). Much attention is being paid to such issues, especially in the literature on development-induced displacement in India, where landlessness is considered the most dangerous problem affecting the displaced.

Children are an insufficiently adaptable group strongly affected by the economic and health consequences of climate change. Progressive desertification in Ghana is a factor in so-called independent child migration - consisting of mobility from the north rural part of the country to the coastal regions and the capital. Decrease in resources results in malnutrition and hence health problems for children. We can highlight here the negative impact of the Asian tsunami on the health of children throughout the affected region.

A characteristic feature of all indigenous peoples is the very strong (organic) relationship with the land and the associated limited capacity to adapt to a new area. More distant resettlement, involving more extreme changes in functioning, has more serious consequences for the human security of the individual and the community.

The growing impact of climate change may be the cause of disintegration or even extermination of rural communities in some countries. Adaptation strategies in response to climate change are highly diverse, with displacement usually the most distant solution. A frequently observed adaptation strategy is migration to towns by young men who send home their money to support the family in rural areas. In the case of famine, migration to cities can reach massive and uncontrolled proportions. Taking into account the increasing population pressure on limited territory and the limited amount of food in cities, this strategy is often misguided. A much better mechanism for overcoming the problems would be the evolution of a new economic model within the existing place of residence. Residents of large metropolitan areas are also in a category of high vulnerability to displacement caused by environmental problems. Agricultural crop failure can result in poor food supply in the cities. Problems with food can cause displacement in the direction of areas with more resources. It is also worth mentioning the danger of rising sea levels. This problem threatens not only cities on the coasts of India, China and Australia, but also the largest European and American metropolises such as London and New York. Other communities significantly affected by climate change are nomadic groups and several categories of illegal settlers without formal rights to land and resources. In the situation of decrease in resources, members of the privileged classes have the best chance of obtaining them. In the situation of potential conflict over resources, people who are already marginalized socially are least likely to obtain the resources needed for existence, being at the end of the queue for such resources.

Cultural security - The emergence of a changed economic model and the erosion of social ties are not the sole consequences of forced migration from areas of climate disruption. Equally important may be the irreversible cultural losses. The three main factors influencing cultural change caused by climate disruption are: 1 . The level of reversibility of the negative changes (and thus the at least potential ability, or lack thereof, to return to the homeland), 2. The level of community cohesion, and 3. Measures to support the social community in the face of dangers of this kind. Long-term residence and ties to the territory are the primary factors in the cultivation of cultural traditions and group cohesion. Displacement breaks these ties. Particularly dangerous in the context of cultural consequences of migration is the displacement which leads to atomization into small groups. According to Francoise Gemenne, climate-induced migrations from Tuvalu may lead to the impoverishment of this country's culture and loss of the multicultural region of Oceania. The 
impact of environmentally-induced displacement on the evolution of the cultural model is also seen in Africa and Asia. Climate change is often the cause of forced rural-urban migrations in several parts of the globe (e.g. Mongolia). This process is evident, for example, in Brazil, Mongolia and some countries in Africa, engendering huge changes in the pattern of life. Inability to maintain previous cultural traditions often results in their gradual abandonment, accompanied by a very weak and drawn-out process of adaptation to the new conditions. Sociological research conducted within the communities displaced by Three Gorges Dam in China, desertification in Mongolia and permanent flooding of the Bhola Island reveal their very difficult and limited adaptation to unfamiliar patterns of life and the impact of the new culture. Disappearance of existing traditions and cultural patterns is accompanied by several forms of marginalization in the new place of residence. The only way to minimize the negative cultural consequences of displacement is to resettle entire communities in territories with a similar profile to those abandoned. The consequence of climate change may be a displacement and atomization of entire communities and hence depletion of cultural traditions, even to the point of language extinction. Rising sea levels and associated deterritorialization of microstates in Oceania could create the most negative cultural change. Nations burdened by climate change will be deprived of the opportunity to maintain their sovereignty and cultural traditions, leading to these nations' gradual absorption by countries which are more stable climatically. The cultural consequences of climate change can be so much stronger than the effects of certain categories of development-induced displacement. Social changes caused by rising sea levels and desertification of soil mass may be incomparably greater than the consequences of limited displacement due to the construction of a dam. Countries with high levels of climatic stability are negligibly vulnerable to this kind of problem. However, their areas can become a target for refugees migrating to escape rising sea levels, desertification and land degradation.

\section{Environmentally-Induced Displacement and Social Change}

The impact of internal displacement on social change within communities affected by its consequences has for many years been the subject of wider research undertaken by sociologists, applied anthropologists and experts in applied development. As early as the fifties, American anthropologist Robert A. Fernea analyzed the social changes associated with the resettlement of tens of thousands of members of the Nubian community as a result of the construction of the High Dam in Aswan. ${ }^{14}$ The beginnings of extensive study of the social consequences of dam construction in South Africa can also be dated back to the early and mid fifties. Here it is worth mentioning the Gwembe Tonga Research Project, initiated in 1956 by the American applied anthropologists Elizabeth Colson and Thayer Scudder. Its primary aim was to analyze the consequences of the construction of the Kariba Dam on the Zambezi River in terms of the social changes experienced by 57,000 Gwembe Tonga people involuntary resettled as a result of the dam's creation. The main purpose of this project, initiated by the Rhodes Livingstone Institute, was to describe the impact of involuntary resettlement on social change within the group of affected people. In the following decades, similar analyses were undertaken by sociologists, applied anthropologists and specialists in applied development, especially those cooperating with World Bank institutions. The creation of large dams leads to the particularly strong transformation of social ties, current economic models and cultural heritage which is associated with flooding of large areas and resettlement of the population to distant territories. We can mention here the situation of 1.2 million people resettled following the construction of Three Gorges Dam on the Yangtze river. Some of them were resettled in the suburbs of large cities, a process which was associated with change in the current model of life. In this case the distant resettlement of people brought about forced adaptation and the need to change their economic profile. The significant scale of negative changes is also associated with

14

R. Fernea, J.G. Kennedy, "Initial Adaptations to Resettlement: A New Life for Egyptian Nubians", Current Anthropology, Vol. 7, 1966, pp. 449-464. 
development projects seen as violating the rights of the local population, some of which have been mentioned previously. Here we can mention further the deterioration in living conditions of the Gwembe Tonga people following the creation of the Kariba Dam on the Zambezi.

Studies of the impact of relocation on the nature of social change, however, are not limited to the phenomenon of development-induced displacement and resettlement. Among other cases, much attention in recent years has been given to the impact of Palestinian displacement on changes in the model of their functioning as well as on demographic change within this community. The problems analyzed include social change within communities of internally displaced persons in Turkey, Afghanistan and Iraq. The long duration of many displacements associated with internal conflicts in such countries as Colombia, Afghanistan, Turkey or Cyprus can provide many very interesting sociological observations. The main focus of research in these cases seems to be the impact of the displacement on the diaspora's effort to maintain its identity. As in the case of development-caused displacement, the more irreversible the displacement and the greater the difference between the new and old models of life, the greater is the potential for social change within the community. People who have the opportunity to return to their homes soon after the conflict ends will probably find it easier to maintain existing social relations than the third or fourth generation of refugees, who have no chance of returning to previously abandoned territories. Belief in the possibility of returning to previously abandoned territories, as exemplified by Palestinians holding on, even for decades, to the keys to their abandoned homes, may be an important factor in protecting the displaced against atomization within larger structures or erosion of their cultural identity. Despite a number of recently conducted field studies of the relationship between displacement and the dynamics of social change within communities, affected IDPs still constitute an underresearched scientific issue. Much more attention has been paid to the changes taking place within the diaspora of refugees and the relationships of this group with the society of their country of residence (that is, the integration or marginalization of foreign refugees within their host communities). The strong dichotomy between strangers (refugees) and nationals of host countries facilitates this kind of research. In the case of IDPs displaced by armed conflicts, but not members of specific minorities, it is difficult to identify specific social changes associated with the displacement. Differences between IDPs and host communities are slight and do not force the integration of displaced people to the point of significant change in the existing operational model. The sphere of much recent sociological research, on both IDPs and international refugees, is confined to the social and cultural context of camps (IDP camps, refugee camps).

We have also observed a growing number of publications analyzing the social changes caused by displacement associated with several categories of environmental disruption. Displacement associated with natural disasters is usually short-term in nature. People affected by natural disasters usually try to return to their homes or to their immediate neighborhoods, in order to recover existing social ties and economic models. The vast majority of local and short-term natural disasters do not generate more distant migrations. For example, people displaced or evacuated due to flooding in the neighborhood typically return to their homes and try to rebuild their former living conditions. One exception in this regard is displacement associated with natural disasters having a huge territorial range and inflicting a high level of damage, like the Asian tsunami of December 2004, resulting in the long-term displacement of hundreds of thousands of people. Because of the large-scale destruction and nearly 350,000 deaths, the social and economic interactions have so far proved very difficult to restore. Another problem leading to significant social change is industrial accidents, the consequences of which affect a large surface area. The explosion at the Chernobyl nuclear reactor led to the decision to force the resettlement of many thousands of people, including the whole town of Pripyat, which was located closest to the nuclear complex. After three days, the 50,000 inhabitants of Pripyat were evacuated, never to return. Pripyat remains empty today. This disaster therefore led to significant social changes, not to mention the health consequences in the contaminated area.

Generally speaking, however, we can say that most displacement caused by natural disasters does not lead to major changes in society. A completely different situation is seen in the case of 
displacement caused by long-term transformations of the environment, especially climate change. Particularly high potential for social transformation can be found in scarcely reversible environmental phenomena involving large areas, especially desertification and soil degradation, and probably also in future demographic effects of the rise in sea level. In the next part of this section I shall discuss a few examples of environmentally-induced displacement which entail significant economic, social and cultural transformation in the lives of people undergoing it.

Progressive land degradation, desertification, salinization and soil erosion are the causes of common problems for many pastoral communities in Africa and Asia, including difficulty in maintaining stocks and the related prospect of poverty for entire families. Soil desertification in Mongolia forced pastoral communities to migrate to slums in the suburbs of the capital city Ulan Bator. The biggest change consists therefore of the need to abandon their nomadic way of life and economic model for a settled existence and the prospect of impoverishment in the slums. Living in the suburbs of Ulan Bator, nomads tend to have great difficulty in finding work. They also have to pay for goods such as wood or drinking water. Despite the worsening of their financial situation they can no longer return to their old way of life. The very rapid transition from the nomadic model of life to a settled economy often causes the erosion of existing social ties and of the cultural heritage transmitted from generation to generation.

The expanding scale of soil desertification and drought is common in many developing countries. In the situation of steadily worsening economic conditions for rural communities, the often observed strategy is to migrate from the countryside to the cities. However, rural-urban migration is not always a good solution, in terms of improving the economic situation and thus maximizing the level of human security. In the case of a prolonged drought and hunger across a large territory, migration to large urban centers is often the elected survival strategy, resulting in food shortages in urban centers. Famine in the Sahel region was observed especially in the years 1968-1974, leading from the early 80s on to the death of many thousands of people, along with increased rural-urban migration. However, rural-urban forced migration was not the most frequently used strategy for improving economic conditions and maximizing human security levels.

Even today, desertification and deteriorating economic conditions form an important pushfactor in forced migration. Quite often, however, migration is not undertaken by the whole family and community but rather by its elected members (especially those of working age). Migration and further self-maintenance by part of the family help other members in areas affected by environmental problems to survive a period of deteriorating economic conditions. Sometimes the money sent by individuals working in other parts of the country help families to survive the harsh conditions. One of the most interesting phenomena leading to significant social change is Ghana's north-south independent child migration. Soil desertification in the northern part of the country has led to mass migration to the southern part of this state ${ }^{15}$. We can therefore observe the transformation of the normal migration pattern of young children - from passive participants in the economic migrations of their parents, to independent young migrant workers undertaking labor migration, which is sometimes also environmentally motivated. Another example of long-term mobility caused by the desertification of soil is the migration of young men from rural areas to the cities in Brazil in the seventies.

A problem that could lead to major economic and social change in future is the rise in sea level accompanied by coastal erosion. Even today, there are cases of Asian cyclones leading to permanent inundation of large areas. The flooding of the island of Bhola in Bangladesh in 1995 forced more than 500,000 people from their homes. Another flood a few years later led to the permanent displacement of residents of the island to the suburbs of Dhaka, Rajshahi, Khulna and Chittagong. As in the case of Mongolian shepherds, forced migration is associated with major social and economic changes.

Rising sea levels cause forced migration both directly and indirectly. The direct effect occurs

15

The phenomenon of independent child migration is currently observed in Burkina Faso, Ghana, Bangladesh and India. 
when permanent flooding of the inhabited area causes displacement to another location. In addition to the already mentioned situation of Bhola island residents, this problem currently affects about 100 inhabitants of Tegua island in the Vanuatu archipelago and a few thousand people in the Carteret islands belonging to Papua New Guinea. Climate change may, however, affect the dynamics of migration in a more indirect manner. Fear of rising ocean levels around the archipelago of Tuvalu has led to the migration of several thousand of its citizens to New Zealand. This migration combines two inseparable economic and environmental motivations. Even the fear of potential changes in the future may be an important push-factor in relocation to another place. The impact of internal resettlement on social changes affecting the community depends on many factors. Among the most important of them we can mention: 1. the territorial scope of environmental changes, 2. the displacement time range (reversible or irreversible), 3. the nature of the new place of residence compared to the one abandoned, 4 . the character and level of cohesion (integration) of the displaced community, and 5. the number of displaced people (mobility of entire communities or single individuals).

The nature of social change caused by displacement is strongly determined by the distance of the new place from the former homeland. Forced migration of an international character (refugee migration) and long and irreversible internal displacement are often associated with high levels of social and cultural change. They result in the need to adjust one's model of life so as to integrate with the new group, or at least develop favorable interactions with its members. The language barrier and low labor flexibility of displaced people hinders their integration in the new place of residence. The consequence of the pursuit of integration and adaptation to new cultural models, however, is often associated with the erosion of existing traditions and community ties. Mobility of persons displaced as a result of long-term changes in the environment has a less planned and formal character than, for example, that of development-induced displaced people. Migrations of this type also are more voluntary in nature than those in the category of development-induced displacement and resettlement, which is characterized by a certain degree of administrative coercion. Motivations of environmentally-forced migrants are sometimes hard to distinguish from voluntary mobility of an economic nature. No less important a factor is the economic and cultural disparity of the new place of residence compared to the abandoned territory. As has been observed in Mongolia, the transition of pastoral communities, for centuries engaged in nomadic life, to the settled model of life causes great economic, social and cultural upheaval. Similarly, the displacement of a rural population located near the suburbs of big cities leads to greater change in their living conditions than their relocation to remote areas where they can maintain their current economic model. The extreme difference between the economic situation in the new place of residence and that in the abandoned area is one of the basic factors promoting far-reaching social change. Forced environmental migrants rarely decide on a sudden and complete change in the current model of economic development. This solution seems to be risky because it appears to be a very cost-effective and longer-term adaptation strategy. For example, studies of the behavior of communities affected by famine in the Sahel region showed that migration to urban areas was not the strategy usually undertaken to maximize the human security of affected populations. Forced migrations associated with long-term environmental processes such as drought or desertification of soil are characterized by a high degree of irreversibility. Awareness of the difficulty of return to the abandoned territory may be one of the factors facilitating adaptation and integration into the new community. In the event of mass displacement of entire communities, it may be much easier to continue with existing social relations and cultural traditions. A much worse situation is observed when environmental changes lead to the atomization of existing communities (e.g. as in the case of the Asian tsunami in December 2004).

\section{References:}

Brauch H.G. (ed.), Security and environment in the Mediterranean: conceptualising security and environmental conflicts, Springer, Berlin, 2003. 
Dalby S., Security and environmental change, Polity, Stafford, 2009.

El-Hinnawi E., Environmental Refugees, UNEP, Nairobi, 1985.

Kavanagh B., Lonergan S., Environmental Degradation, Population Displacement and Global Security, Canadian Global Change Program, Technical Report, December 1992.

Lewis N., "Island in a Sea of Change: Climate Change, Health and Human Security in Small Island States" [In] H.J.S. Fernando, Z.B. Klaić, J.L. McCulley (eds.), National Security and Human Health Implications for Climate Change, Springer, 2011.

Bogardi J., "Hazards, risks and vulnerabilities in a changing environment: The unexpected onslaught on human security?", Global Environmental Change, vol. 14, 2004, pp.361-365.

Warner K., Afifi T., Dun O., Stal M., Schmidl S., Human Security, Climate Change and Environmentally Induced Migration, United Nations University - Institute for Environment and Human Security, June 2008.

Suhrke A., Pressure Points: Environmental Degradation, Migration and Conflict, American Academy of Art and Science, 1993.

Terminski B., Environmentally-Induced Displacement. Theoretical Frameworks and Current Challenges, CEDEM Research Paper, Universite de Liege, 2012.

Terminski B., Oil-induced displacement and resettlement. Social problem and human rights issue, available at: School for International Studies, Simon Fraser University, Human Security Gateway Project, March 2012.

Terminski B., The concept of human security as a tool for analysing the consequences of development-induced displacement and resettlement, available at: School for International Studies, Simon Fraser University, Human Security Gateway Project, October 2012.

Terminski B., Applying the concept of human security to research on the consequences of mininginduced displacement and resettlement, available at: School for International Studies, Simon Fraser University, Human Security Gateway Project, October 2012.

Termiński B., Międzynarodowa ochrona pracowników migrujacych: Geneza, instytucje, oddziaływanie, Wydawnictwa Uniwersytetu Warszawskiego, Warszawa, 2011.

Terminski B., Mining-induced displacement and resettlement. Social problem and human rights issue, Research Paper, Geneva, 2012.

Terminski B., Przesiedlenia inwestycyjne: Nowa kategoria przymusowych migracji, Oficyna Wydawnicza Łośgraf, Warszawa, 2012.

Terminski B., Uchodźstwo srodowiskowe: O ludziach $w$ pułapce natury, Oficyna Wydawnicza Łośgraf, Warszawa, 2013.

Abstract: We can distinguish two general causes of internal displacement worldwide: 1. the impact of threats to and ensuing decline in the level of human security below that needed for normal existence in the homeland territory, 2. administrative compulsion to leave the current place of 
residence. Every year, at least tens of millions of people on all continents are forced to leave their places of residence. The predominant cause is the occurrence of natural disasters, creating the most dynamic category of internal displacement. According to IDMC estimates, natural disasters expelled 42 million people from their homes in 2010 and 14 million people in 2011. Many cases of internal displacement are associated with the accelerating dynamics of climate change, which is a much more long-term phenomenon. The causes of this kind of displacement are the desertification of soils and potential rise in sea level. The aim of this paper will be to determine the impact on several areas of human security of long-term environmental change and the displacement it causes.

The objective of this work is to draw attention to the impact of climate change on internal displacement as an important factor affecting the security of millions of inhabitants of our planet. Relevant considerations have been preceded by an analysis of the most important causes of internal displacement. Among them we can mention: 1. internal armed conflicts and escalation of violence, 2. discrimination, persecution, and repression by state authorities or other political actors, 3 . natural or man-made disasters, 4. long-term environmental changes, 5. economic development, 6. conservation of nature, and 7. specific combinations of political, economic or environmental factors (such as famine). In the next section I draw attention to the historical examples of long-term displacement caused by climate change. Environmental factors and declining resources have been the root cause of migration over most of human history. Only the consequences of the Neolithic (r)evolution and the gradual emancipation from the forces of nature resulted in a greater diversity of contemporary migrations.

The most important section of the work draws attention to the decline in the level of human security associated with long-term environmental processes and the displacement they cause. The consequences can be both violent conflicts for space and resources as well as more peaceful migrations in search of better living conditions. A useful research tool in analyzing such processes has been the classification of seven areas of human security included in the UNDP Human Development Report published in 1994. I have expanded this classification by adding two areas: cultural security, and risks affecting the groups most vulnerable to the negative consequences of environmental change. Among those I have mentioned are: women, children, the elderly, indigenous people, illegal settlers, those with no formal rights to land or resources, and other categories of minorities.

Bogumil Termiński is a specialist in the field of social and economic human rights and the social dimension of migration. He is the author of three books: International protection of migrant workers. Origins, Institutions and impact. (Warsaw University Press, 2011), Development-Induced Displacement: Theoretical Frameworks and Current Challenges (Losgraf Publishers, 2012) and Environmentally-Induced Displacement: Theoretial Frameworks and Current Challenges (University of Liege, 2012), as well as a number of analytical reports published by leading international humanitarian institutions (including the UNHCR in Geneva). 